\title{
24-hours ahead wind speed prediction for the optimum operation of hybrid power stations with the use of artificial neural networks
}

\author{
Moustris K.P. ${ }^{*}{ }^{*}$, Zafirakis D. ${ }^{2}$, Alamo D.H. ${ }^{3}$, Nebot Medina R.J. ${ }^{3}$ and \\ Kaldellis J.K. ${ }^{2}$
}

\author{
1 Laboratory of Fluid Mechanics, Mechanical Engineering Department, Technological \\ Education Institute of Piraeus, 250 Thivon and P. Ralli Str., GR-12244 Athens, Greece \\ 2 Soft Energy Applications \& Environmental Protection Lab, Mechanical Engineering \\ Department, Technological Education Institute of Piraeus, 250 Thivon and P. Ralli Str., GR- \\ 12244 Athens, Greece \\ 3 Instituto Tecnológico de Canarias S.A., Cebrián 3, 35003 Las Palmas de Gran Canaria, \\ Spain \\ *corresponding author e-mail: kmoustris@yahoo.gr
}

\begin{abstract}
Remote areas are usually fed-in terms of electricity supply-from conventional generators that run on diesel. Recently, there is increasing interest on hybrid RES-based systems, including wind and solar power coupled with energy storage. To this end, optimum dispatching of such configurations is largely based on the capacity of prognostic tools employed in the respective energy management system. Acknowledging this, the aim of this work is the prediction of wind speed, 24hours ahead on an hourly basis, for the optimum operation of hybrid power stations (HPS) with the use of artificial neural networks (ANN). For this purpose, hourly data of wind speed have been used at a specific location (Tilos Island, Greece) where a HPS is going to be installed, including also a wind turbine of $800 \mathrm{~kW}$. More specifically, an ANN which is fed with historical wind and air pressure data was developed in order to predict the wind speed at hub height on an hourly basis for the next 24 hours. Results indicate that the proposed methodology gives an adequate forecast of wind speed in order to design an automated wind power information tool that could much facilitate the tasks of the energy management system.
\end{abstract}

\section{Introduction}

Renewable energy, especially wind energy, is rapidly being integrated into electric power systems throughout the world. Due to the high variability and limited forecasting ability of wind speed, current power systems scheduling methods 
face challenges in integrating large-scale wind power. Accurate wind speed prediction is crucial in reducing the uncertainty from the supply side in the power system scheduling. (Zhu et al. 2014). A great number of scientists all over the world have proposed numerous methodologies for short-term forecasts of wind speed a few hours ahead using purely statistical methods, artificial neural networks, probabilistic forecasting models, etc (Brown et al. 1984, Kretzschmar et al. 2004, Gneiting et al. 2006, Nielsen et al. 2006, Genton and Hering 2007, Louka et al. 2008, Sloughter et al. 2010, Cassola and Burlando 2012, Zhu et al. 2014, Zjavka 2015, Liu et al. 2015, Hu et al. 2016, Men et al. 2016).

In the present work an artificial neural network model was developed in order to forecast the mean hourly wind speed 24-hours ahead on an hourly basis for a specific location, $30 \mathrm{~m}$ above ground level (a.g.1.) in Tilos Island, Greece, where a wind turbine of $800 \mathrm{~kW}$ is going to be installed.

\section{Data and methodology}

Artificial neural networks are a branch of artificial intelligence developed in the 1950s aiming at imitating the biological brain architecture. They are an approach to the description of functioning of human nervous system through mathematical functions. Typical ANNs use very simple models of neurons. These artificial neurons models retain only very rough characteristics of biological neurons of the human brain (McCulloh and Pitts, 1943). In this work a Multi-Layer Perceptron (MLP) ANN model (Moustris et al. 2010, Nastos et al. 2011) was trained properly to forecast wind speed $30 \mathrm{~m}$ a.g.l. For the appropriate ANN training mean hourly values of wind speed, wind direction and air pressure at the specific location were used. These meteorological data have been calculated by one minute step records. More specifically, a meteorological mast was installed in the specific location measuring the above meteorological parameters $30 \mathrm{~m}$ a.g.l every minute. The collected data cover the time period from $17 / 03 / 2015$ up to $20 / 12 / 2015$.

Initially, a data file with the available mean hourly values consisting of 6696 cases (279 days x 24 hours) was shaped. This file contains the input and output data for the training of the developed ANN. Table 1 presents the input and output data which were used for the training of the developed ANN model.

For the appropriate ANN training the initial data set was separated in three subsets. The first subset consists $60 \%$ of the available data and was used for ANN training. The second subset consists (randomly selected group of data) $20 \%$ of the available data and was used for the cross validation test and the third subset consists of the rest (randomly selected group of data) $20 \%$ of the available data and was used for the testing phase in order the forecasting accuracy of the developed ANN model to be examined. For the evaluation of the forecasting ability of the proposed wind speed methodology appropriate statistical evaluation indices were applied (Moustris et al. 2010, Nastos et al. 2011). 
Table 1. Description of input and output data.

\begin{tabular}{lll}
\hline & $\checkmark$ & The month $(3, \ldots, 12)$ \\
& $\checkmark$ & $\begin{array}{l}\text { The prevailing hourly wind direction of the previous } 24 \text { hours in } \\
\text { degrees (24 hourly values) }\end{array}$ \\
Input data & $\checkmark$ & $\begin{array}{l}\text { The mean hourly air pressure of the previous } 24 \text { hours in } \mathrm{hPa}(24 \\
\text { hourly values) } \\
\text { The mean hourly wind speed of the previous } 24 \text { hours in } \mathrm{m} / \mathrm{s} \text { (24 } \\
\text { hourly values) }\end{array}$ \\
$\begin{array}{l}\text { Output } \\
\text { data }\end{array}$ & $\checkmark \begin{array}{l}\text { The mean hourly wind speed for the next } 24 \text { hours in hourly bases } \\
\text { in } \mathrm{m} / \mathrm{s} \text { (24 forecasted values) }\end{array}$ \\
\hline
\end{tabular}

\section{Results}

The developed ANN model is exclusively based on historical data. This is an advantage in operational planning due to the fact that there is not any dependency on other data such as numerical weather prediction data in order for the forecast of wind speed to be made.

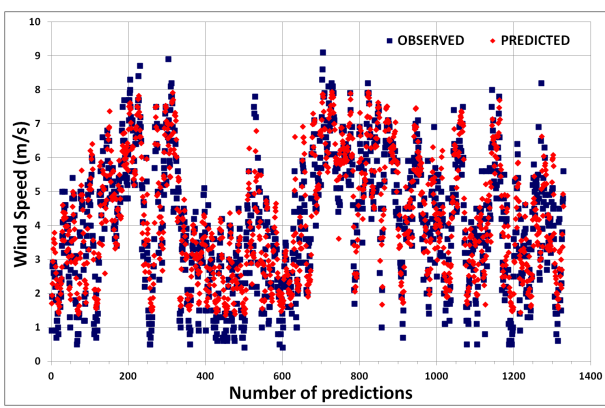

(a)

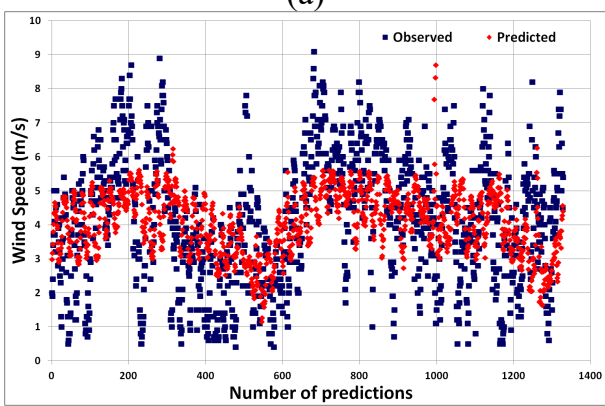

(c)

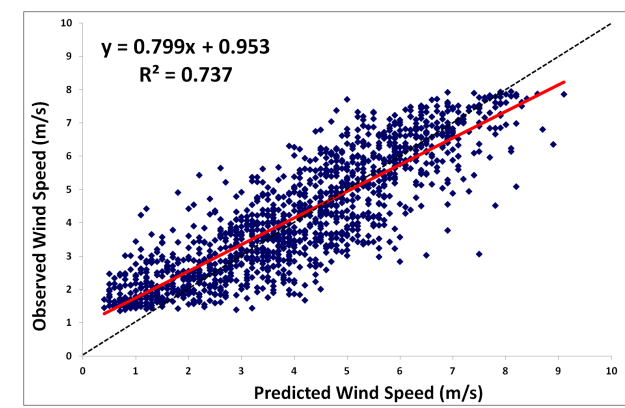

(b)

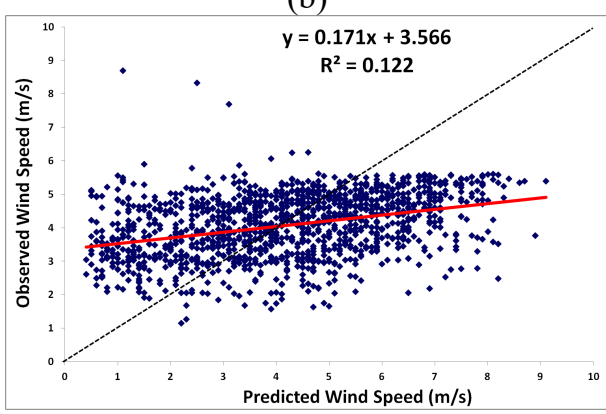

(d)

Fig. 1. Observed vs Predicted mean hourly wind values 1 hour ahead (a) and 24 hours ahead (c). Scaterrplots between the Observed and Predicted mean hourly wind values 1 hour ahead (b) and 24 hours ahead (d). 
Furthermore, the proposed ANN model is a dynamic model that is able to give an adequate forecast of the mean hourly wind speed for the next 24 hours, every next hour of the day. Figures 1a,b show the 1-hour ahead forecasts and Figures 1c, d depict the 24-hours ahead forecasts.

According to Figure 1, for the next hour the predicted mean hourly wind speed values are very close to the corresponding observed values. The coefficient of determination is equal to 0.737 which indicates that the developed forecasting model is able to explain $73.7 \%$ of the variance of wind speed values 1 hour ahead. Concerning the prognosis 24 hours ahead, the coefficient of determination takes the value 0.122 which indicates that the developed forecasting model is able to explain only $12.2 \%$ of the variance of wind speed values 24 hours ahead. Despite this limit value, Figure 1c shows that the model captures the trend of wind speed 24 hours ahead at a very good level.

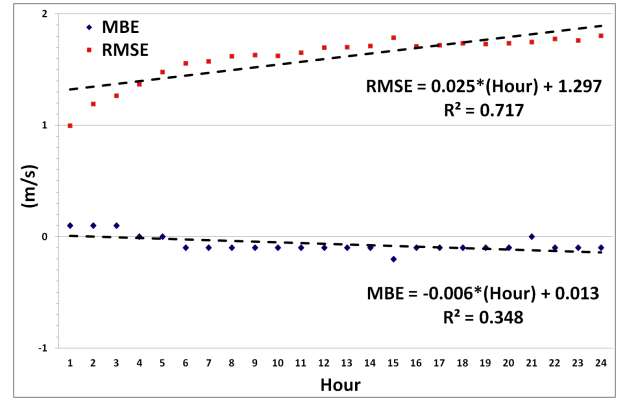

(a)

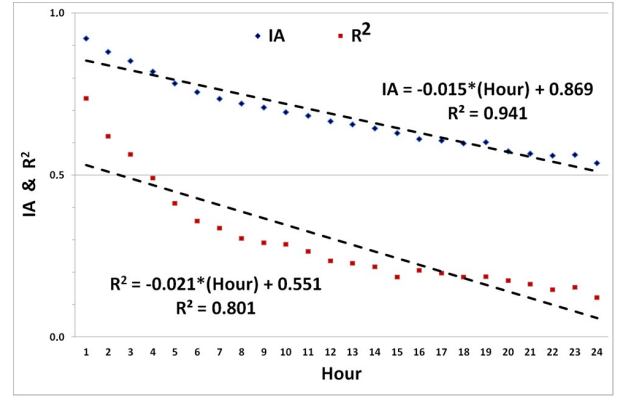

(b)

Fig. 2. Values and trends of the evaluation statistical indices MBE and RMSE (a) and IA and $\mathrm{R}^{2}$ (b) for the 24 hours of prognosis. Period 2001-2013.

In order for the forecasting ability of the proposed ANN model to be examined in depth, the values of root mean square error (RMSE), the mean bias error (MBE), the coefficient of determination $\left(\mathrm{R}^{2}\right)$ and the index of agreement (IA) for every forecasting hour ahead (1-24) were calculated (Moustris et al. 2010, Nastos et al. 2011). Figure 2 depicts the values and the trends of the aforementioned evaluation statistical indices. According to Figure 2a, it seems that the RMSE $(\mathrm{m} / \mathrm{s})$ ranges between $0.997 \mathrm{~m} / \mathrm{s}$ and $1.803 \mathrm{~m} / \mathrm{s}$ and the MBE ranges between $-0.067 \mathrm{~m} / \mathrm{s}$ and $1.000 \mathrm{~m} / \mathrm{s}$. This indicates that as the forecasting time passes, the predictive ability of the developed model decreases presenting nevertheless a small trend $(+0.025 \mathrm{~m} / \mathrm{s}$ for the RMSE for every forecasting hour and $-0.006 \mathrm{~m} / \mathrm{s}$ concerning the MBE which indicates that the model underestimates wind speed as the forecasting time passes).

Additionally, Figure $2 \mathrm{~b}$ depicts that $\mathrm{R}^{2}$ ranges between 0.737 and 0.122 and IA ranges between 0.923 and 0.538 . This indicates that a decreasing trend also for both $\mathrm{R}^{2}$ and IA appears, although within a small range. More specifically, an hour- 
ly trend of $-2.1 \%$ was presented for the ability of the developed ANN model to explain the variance of wind speed values 1 up to 24 hours ahead. Also, an hourly trend of -0.015 for IA was presented which means that as the forecasting time passes the predicted wind speed values present greater distance from the observed wind speed values. Despite that, it can be argued that the prediction is satisfied even for 24 hours ahead ( $I A=0.538)$, mainly due to the nature of the application that does not require precise forecast but the knowledge of the wind speed trend in a fairly good approximation.

\section{Conclusions}

An ANN wind speed forecasting model was presented in this work. The evaluation of the proposed methodology shows that adequate prognosis of the mean hourly wind speed -at a specific location where a wind turbine of $800 \mathrm{~kW}$ is going to be installed- is possible even for 24-hours ahead. It should be noted here that according to the results of the proposed methodology the forecasting ability seems to be enough adequate, for such an application, only for the next three (3) consecutive hours. Despite this limitation, the validity of the proposed methodology is quite satisfactory. This is due to the fact that it is a dynamic process which provides new and updated predictions every single hour of the day ( 24 forecasts per day for the next 24 consecutive hours).

Authors believe that by this way the system administrator will be able to have a very good point of view concerning wind speed for the next three consecutive hours as well as a picture of the possible trend of hourly wind speeds for the next 24 hours. This is an optimistic result in order to design an automated wind power information tool that could much facilitate the tasks of the energy management system. In any case, further investigation is encouraged so as to increase the forecasting ability of the proposed wind speed dynamic forecasting model using, in a parallel process as primary inputs, data from numerical weather prediction models.

\section{Acknowledgment}

This work took place and was funded under the project TILOS (Horizon 2020 Low Carbon Energy Local / small-scale storage LCE-08-2014). This project has received funding from the European Union's Horizon 2020 research and innovation programme under Grant Agreement No 646529.

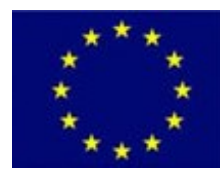




\section{References}

Brown BG, Katz RW, Murphy A H (1984) Time Series Models to Simulate and Forecast Wind Speed and Wind Power. J Clim Appl Meteorol 23:1184-1195

Cassola F, Burlando M (2012) Wind speed and wind energy forecast through Kalman filtering of Numerical Weather Prediction model output. Appl Energ 99:154-166

Genton M, Hering A (2007) Blowing in the Wind. Significance 4:11-14

Gneiting T, Larson K, Westrick K, Genton MG, Aldrich E (2006) Calibrated Probabilistic Forecasting at the Stateline Wind Energy Center: The Regime-Switching Space-Time Method. J Am Stat Assoc 101:968-979

Hu Q, Zhang R, Zhou Y (2016) Transfer learning for short-term wind speed prediction with deep neural networks. Renew Energ 85:83-95

Kretzschmar R, Eckert P, Cattani D, Eggimann F (2004) Neural Network Classifiers for Local Wind Prediction. J Appl Meteorol 43:727-738

Liu H, Tian H, Liang X, Li Y (2015) New wind speed forecasting approaches using fast ensemble empirical model decomposition, genetic algorithm, Mind Evolutionary Algorithm and Artificial Neural Networks. Renew Energ 83:1066-1075

Louka P, Galanis G, Siebert N, Kariniotakis G, Katsafados P, Kallos G, Pytharoulis I (2008) Improvements in wind speed forecasts for wind power prediction purposes using Kalman filtering. J Wind Eng Ind Aerod 96(12):2348-2362

McCulloh WS, Pitts W (1943) A logical calculus of ideas immanent in Nervous activity. Bulletin of Mathematical Biophysics B Math Biophys 5:115-133

Men Z, Yee E, Lien F-S, Wen D, Chen Y (2016) Short-term wind speed and power forecasting using an ensemble of mixture density neural networks. Renew Energ 87:203-211

Moustris KP, Ziomas IC, Paliatsos AG (2010) 3-Day-Ahead Forecasting of Regional Pollution Index for the Pollutants $\mathrm{NO} 2, \mathrm{CO}, \mathrm{SO}$, and $\mathrm{O} 3$ Using Artificial Neural Networks in Athens, Greece. Water Air Soil Poll 200:29-43

Nastos P, Moustris K, Larissi I, Paliatsos A (2011) Air Quality and Bioclimatic Conditions within the Greater Athens Area, Greece-Development and Applications of Artificial Neural Networks. Advanced Air Pollution, InTech-Open Access (ISBN: 978-953-307-511-2):557-584

Nielsen TS, Madsen H, Nielsen HAa, Pinson P, Kariniotakis G, Siebert N, Marti I, Lange M, Focken U, Lueder V, Bremen LV, Louka P, Kallos G, Galanis G (2006) Short-term Wind Power Forecasting Using Advanced Statistical Methods. The European Wind Energy Conference, EWEC 2006, Feb 2006, Athenes, Greece, 9-17

Sloughter JM, Raftery AE, Gneiting T, Fraley C (2007) Probabilistic Quantitative Precipitation Forecasting Using Bayesian Model Averaging. Mon Weather Rev 135:3209-3220

Zhu X, Marc G. Genton MG, Gu Y, Xie L (2014) Space-time wind speed forecasting for improved power system dispatch. TEST 23:1-25

Zjavka L (2015) Wind speed forecast correction models using polynomial neural networks. Renew Energ 83:998-1006 